\title{
Application of Piecewise Linear Approximation Method for the Estimation of Origin-Destination Matrix
}

\author{
Miguel Fernández ${ }^{1}$, Enrique Lee Huamaní ${ }^{2}$, Aldo Fernández ${ }^{3}$, Avid Roman-Gonzalez ${ }^{4}$ \\ Department of Engineering, Pontifical Catholic University of Peru, Lima 32, Peru ${ }^{1}$ \\ Image Processing Research Laboratory, Universidad de Ciencias y Humanidades Lima, Perú ${ }^{1,2,4}$ \\ Instituto de computacion, Universidad Federal de Fluminense, Rio de Janeiro, Brazil ${ }^{3}$
}

\begin{abstract}
This paper presents a Mixed-Integer Programming Model for the urban freight transport planning problem through the estimation of the Origin-Destination Matrix. The OriginDestination Matrix is used to know the pattern of travel or vehicle flow between different zones of a city and is estimated from the counting of vehicles on the routes of a road network. For the estimation of the Origin-Destination Matrix, the Entropy Maximization approach is applied. This approach is based on a non-linear optimization model. In order to overcome this difficulty, an optimization model based on the Piecewise Linear Approximation Method is proposed. To test the proposed model, an instance was built based on a road network of a real case. The proposed model obtained good results in a reduced computational time, demonstrating its usefulness for the urban freight transport planning.
\end{abstract}

Keywords-Urban freight transport; origin-destination matrix; mixed-integer programming model; piecewise linear approximation method

\section{INTRODUCTION}

The problem of urban freight transport (freight transit or goods orders), is one of the most complex and challenging problems facing the public sector, since it is responsible for financing new road infrastructure or improvements in these. The flow of cargo vehicles normally has a much more complicated distribution than the flow of private vehicles or public transport, this because cargo vehicles make multiple stops in different parts of the city and have different routes for the delivery of goods to consumers, besides considering aspects related to the supply chain of the different companies [1] [2] [3]. The study of this problem should be aimed at satisfying the needs and expectations of companies and consumers by suppliers, who are responsible for the delivery of goods [4]. In [5] Point out that one of the key factors of a city's economy is consumer behavior. The consumer is responsible for the demand and the generation of freight transport. In this way, the need arises to optimize urban freight transport, which guarantees a fast and reliable delivery of goods at the lowest shipping cost; that contemplates changes in demand; and ensure good decision making regarding future investments in the city's road infrastructure.

According to [6] to carry out the modeling of urban freight transport requires a large amount of data, among which we can highlight:
Frequency of trips;

Delivery routes;

Location of customers;

Amount of goods carried per vehicle;

Data related to shippers (timetables, warehouse location, inventory policies);

Data related to receivers (size of premises, number of employees, revenue).

According to [7], the modeling of urban freight transport should focus mainly on the flow of cargo, which is related to road infrastructure and the freight transit between suppliers (origin) and consumers (destination). This modeling is based on estimating the Origin-Destination Matrix (OD Matrix), which measures the level of vehicle congestion in a future road network [8]. The OD Matrix stores the travel information of an urban area and is of great importance in transportation planning. The knowledge about trip flows is usually organized in the form of two-dimensional matrices called the OD matrices, whose cell values represent the travel demand between each given origin (row) and destination (column) zone. One of the most crucial requirements for the transportation planning is to arrive at the traffic pattern between various zones through OD matrix estimation [9] [10].

Among the most important works using the OD matrix can be cited: [11] [12] [13] [14] [6] [15] [16] [17] .

As highlighted [6], the importance of having tools to model changes in urban traffic before their implementation, since they involve social and political risks. As indicated [9], there is no universal technique for modelling urban transport and alternative forms need to be developed. Therefore, this document proposes a new method to estimate the OD matrix for urban freight transport through maximization of entropy.

This paper is organized as follows: Section 2 describes the OD Matrix. In Section 3, the entropy maximization model is described and presents the proposed mathematical model. In Section 4, a computational experiment is performed to evaluate the performance of the mathematical model proposed by a fictitious instance. Section 5 provides conclusions of this paper. 
TABLE I. REPRESENTATION OF THE OD MATRIX

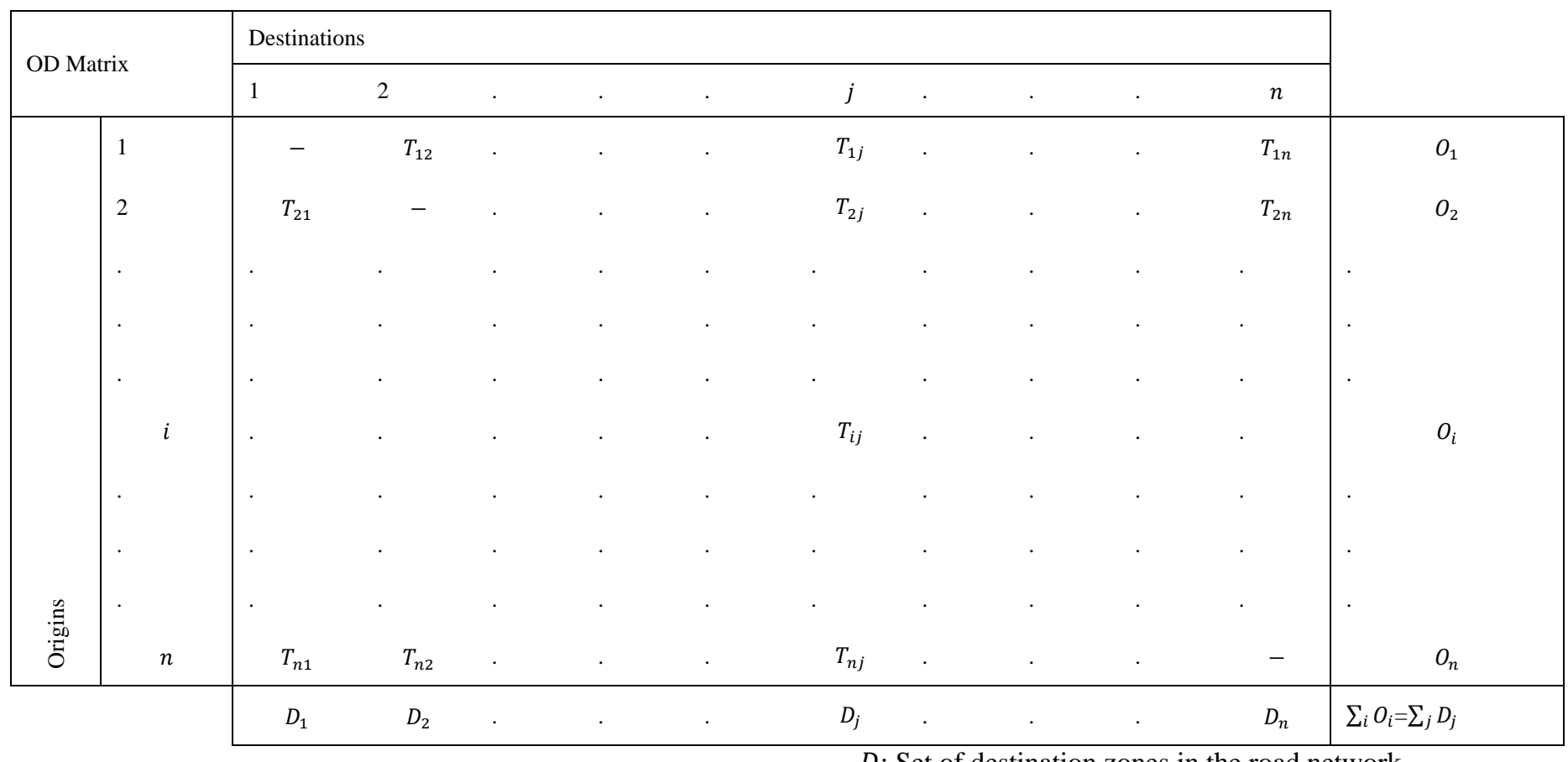

II. TRAVEL MATRIX

A travel matrix or also called OD Matrix is a square matrix, where the cell of each row stores the number of trips originating from one zone to another. The rows of the matrix correspond to the zones of origin and the columns of the matrix correspond to the zones of destination. Table I shows the representation of the OD Matrix.

\section{ENTROPY MAXIMIZATION FOR ESTIMATION OF OD MATRICES}

The entropy maximization model is used to find trips patterns that are as distributed as possible along the OD matrix based on volumetric counts in the various arcs or routes of a road network. According to [6], in the case of urban freight transport, entropy approach is more suitable than other gravitytype approaches [18] [19] [20]. This is because delivery tours in the entropy approach are designated based on commercial considerations (customer locations or time windows); and not to proximity and cost considerations as in gravity-type approaches.

The entropy maximization model is based on vehicle counting between the different routes of the road network and previous information from a study (Root Matrix).

The following nomenclature is used to formulate this model:

\section{Indexes}

$i, j$ : Index of road network zones.

$a$ : Index of road network arcs.

Sets

$O:$ Set of origin zones in the road network.
$D$ : Set of destination zones in the road network.

$A$ : Set of arcs of the road network observed in the volumetric count.

Parameters

$t_{i j}$ : Total trips from origin $i$ to destination $j$ in the Root Matrix.

$p_{i j}^{a}$ : Proportion of trips corresponding to the OriginDestination pair $(i, j)$ that pass through the arch to $a$.

$V_{a}$ : Volume observed over the arc $a$.

Variables

$T_{i j}$ : Total trips from origin $i$ to destiny $j$

The entropy maximization model is formulated as follows:

$\operatorname{Max} W=-\sum_{(i, j)} T_{i j} \log \left(T_{i j}\right)+\sum_{(i, j)} T_{i j} \log \left(t_{i j}\right)$

Subject to:

$\sum_{(i, j)} p_{i j}^{a} T_{i j}=V_{a} \quad \forall a$

$T_{i j} \geq 0 \forall(i, j) \mid(i, j) \in O \times D$

In this mathematical model, the objective function (1) represents the maximization of entropy. Note that the restriction (2) establishes that the sum of the proportion of trips of the different origin-destination pairs that pass through an arc, is equal to the total trips observed in said arc. Constraint (3) defines the domain of the decision variable $T_{i j}$. The variable $T_{i j}$ is declared only among those origin-destination zones, in which there is a route that connects them. 
For this problem not to generate a degenerate or infeasible solution, it must be met: $|O|+|D|-1=|A|$. Where the function $|$.$| determines the number of elements in a set. This$ relationship is known in transport models and indicates that it is not necessary to establish counting points on all routes of the road network, but only at strategic counting points. [9] Recommend avoiding collect volumes on links that may not be independent, as they generate linearly dependent equations and affect the accuracy of the estimated OD matrix.

Note that the objective function (1) is not a linear expression, therefore, this model cannot be solved by classical optimization methods. Moreover, in real cases, the application of the model can present a large number of variables and restrictions, due to the large number of nodes in the road network. To overcome these difficulties, a Mixed-Integer Programming Model based on the Piecewise Linear Approximation Method is proposed. The Piecewise Linear Approximation Method is a useful method to transform nonlinear functions into a weighted sum of linear terms [21].

Following is the reformulation of the entropy maximization model using the Piecewise Linear Approximation Method:

$\operatorname{Max} W=-\sum_{(i, j)} R_{i j}+\sum_{(i, j)} T_{i j} \log \left(t_{i j}\right)$

Subject to:

$\sum_{(i, j)} p_{i j}^{a} T_{i j}=V_{a} \quad \forall a$

$\sum_{b} \tilde{T}_{i j b} \lambda_{i j b}=T_{i j} \quad \forall(i, j)$

$\sum_{b} \tilde{T}_{i j b} \log \left(\tilde{T}_{i j b}\right) \lambda_{i j b}=R_{i j} \quad \forall(i, j)$

$\sum_{b} \lambda_{i j b}=1 \quad \forall(i, j)$

$\sum_{b<B} S_{i j b}=1 \quad \forall(i, j)$

$S_{i j B}=0 \quad \forall(i, j)$

$F_{i j 1}=S_{i j 1} \quad \forall(i, j)$

$F_{i j b}=S_{i j, b-1}+S_{i j, b} \quad \forall(i, j), b>1$

$\lambda_{i j b} \leq F_{i j b} \quad \forall(i, j), b$

$T_{i j} \geq 0, R_{i j} \geq 0 \quad \forall(i, j) \mid(i, j) \in O \times D$

$\lambda_{i j b} \geq 0 \forall(i, j), b \mid(i, j) \in O \times D$

$S_{i j b} \in\{0,1\}, F_{i j b} \in\{0,1\} \forall(i, j), b \mid(i, j) \in O \times D$

In this proposed mathematical model, the objective function (4) represents the maximization of entropy. The restriction (5) establishes that the sum of the proportion of trips of the different origin-destination pairs that pass through an arc, is equal to the total trips observed in said arc. The constraint (6) determines the value of the variable $T_{i j}$ by a weighted sum of a pair of adjacent points generated from the segmentation of the range of the variable $T_{i j}$. In this restriction $b$ represents the index of the segmentation of the range of the variable $T_{i j} ; \tilde{T}_{i j b}$ the value corresponding to each segmentation of the range of the variable $T_{i j}$; and $\lambda_{i j b}$ the weight assigned each segmentation of the range of the variable $T_{i j}$. The constraint (7) determines the value of the non-linear expression $T_{i j} \log \left(T_{i j}\right)$ through a weighted sum of the evaluation of a pair of adjacent points. Restriction (8) states that the sum of pesos must be equal to one. Restrictions (9) and (10) ensure that a point of segmentation is selected within the range of the variable $T_{i j}$; here $B$ represents the number of points generated from the segmentation of the range of the variable $T_{i j}$. Restrictions (11) and (12) ensure that if a point was selected, then its corresponding adjacent point is also selected. The restriction (13) establishes that those selected points have assigned non-zero weights; those unselected points have zero weights. Constraints (14) - (16) define the domain of the decision variables.

\section{COMPUTATIONAL EXPERIMENT}

The mathematical model proposed in the previous section will be evaluated in an instance based on the road network of a real case. This road network is shown in Fig. 1. In this road network, the nodes $\{A, B, C, D, E, F\}$ they represent the zones of origin; nodes $\{M, P, V\}$ represent the target zones; and the arcs that connect the nodes $\{1,2, \ldots, 16\}$ represent the routes.

Table II presents the number of possible routes between each origin-destination pair, the proportion of trips in the different arches and the total trips observed in the arcs. Table III shows the Root Matrix.

The mathematical model was implemented in the AMPL software using the CPLEX 12.9 solver and run on a computer equipped with an Intel Core i3-2310M processor with $2.1 \mathrm{GHz}$ and 4 GB of RAM. To solve the problem, 1000 segments and a GAP of $0 \%$ were used.

Table IV shows the OD Matrix obtained by the proposed mathematical model. Comparing to Table III and Table IV, it is observed that both the most important origin zone and the most important destination zone have not changed (zone with the highest number of trips produced or destined); however, the most important Origin-Destination connection has changed for D-M, note that it was previously F-M. Fig. 2 compares the trips generated between the Root Matrix and the OD Matrix estimated, showing the increase and decrease produced after a specific period of time. Fig. 3 details the levels of increase in the trips generated, where the green, red and orange bars indicate increases of less than $15 \%, 15 \%$ to $25 \%$, and more than $25 \%$, respectively. This information is useful for transportation planning and can serve as a basis for executing new road works or proposing restrictions on the flow of freight vehicles. 


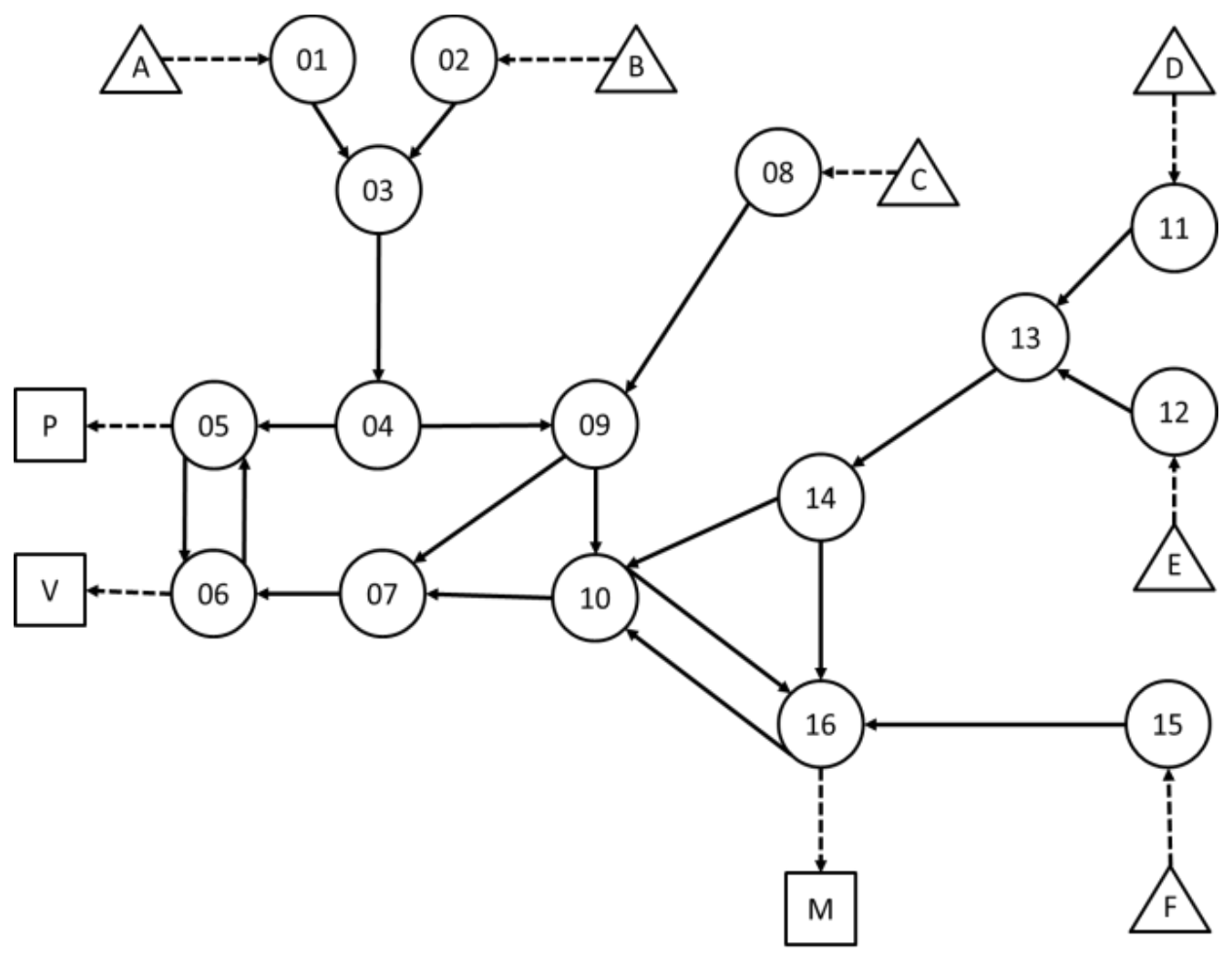

Fig. 1. Road Network of the Generated Instance.

TABLE II. TRAVEL OF EXISTING ROUTES BETWEEN ORIGIN-DESTINATION ZONES

\begin{tabular}{|c|c|c|c|c|c|c|c|c|c|}
\hline & & 1 & 2 & 3 & 4 & 5 & 6 & 7 & 8 \\
\hline $\begin{array}{l}\text { Origin- } \\
\text { destiny }\end{array}$ & $\begin{array}{l}\text { Number of } \\
\text { routes }\end{array}$ & 04-05 & 04-09 & 09-07 & $10-16$ & $16-10$ & $15-16$ & $10-07$ & $14-16$ \\
\hline A-P & 1 & 1.00 & & & & & & & \\
\hline $\mathrm{A}-\mathrm{V}$ & 2 & 0.73 & 0.27 & 0.27 & & & & & \\
\hline A-M & 1 & & 1.00 & & 1.00 & & & & \\
\hline $\mathrm{B}-\mathrm{P}$ & 1 & 1.00 & & & & & & & \\
\hline $\mathrm{B}-\mathrm{V}$ & 2 & 0.64 & 0.36 & 0.36 & & & & & \\
\hline B-M & 1 & & 1.00 & & 1.00 & & & & \\
\hline $\mathrm{C}-\mathrm{P}$ & 2 & & & 0.82 & & & & & \\
\hline $\mathrm{C}-\mathrm{V}$ & 2 & & & 0.82 & & & & & \\
\hline $\mathrm{C}-\mathrm{M}$ & 1 & & & & 1.00 & & & & \\
\hline D-P & 2 & & & & & 0.45 & & 1.00 & 0.45 \\
\hline $\mathrm{D}-\mathrm{V}$ & 2 & & & & & 0.45 & & 1.00 & 0.45 \\
\hline D-M & 1 & & & & & & & & 1.00 \\
\hline E-P & 2 & & & & & 0.43 & & 1.00 & 0.43 \\
\hline E-V & 2 & & & & & 0.43 & & 1.00 & 0.43 \\
\hline E-M & 1 & & & & & & & & 1.00 \\
\hline F-P & 1 & & & & & 1.00 & 1.00 & 1.00 & \\
\hline $\mathrm{F}-\mathrm{V}$ & 1 & & & & & 1.00 & 1.00 & 1.00 & \\
\hline F-M & 1 & & & & & & 1.00 & & \\
\hline \multicolumn{2}{|c|}{ Total trips observed } & 1260 & 770 & 1020 & 1064 & 550 & 794 & 1100 & 980 \\
\hline
\end{tabular}


TABLE III. ROOT MATRIX ORIGIN-DESTINATION

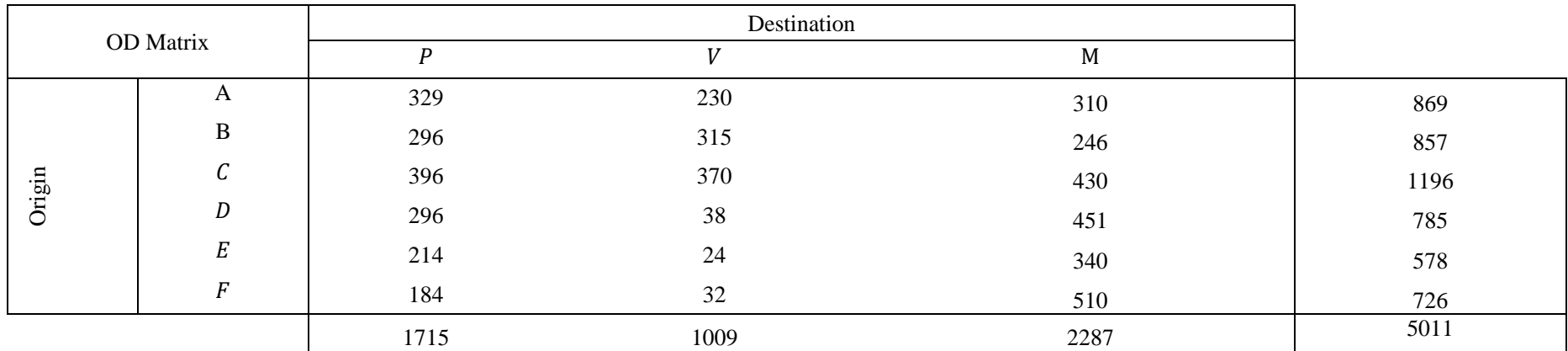

TABle IV. Computational Result of the Proposed Mathematical Model

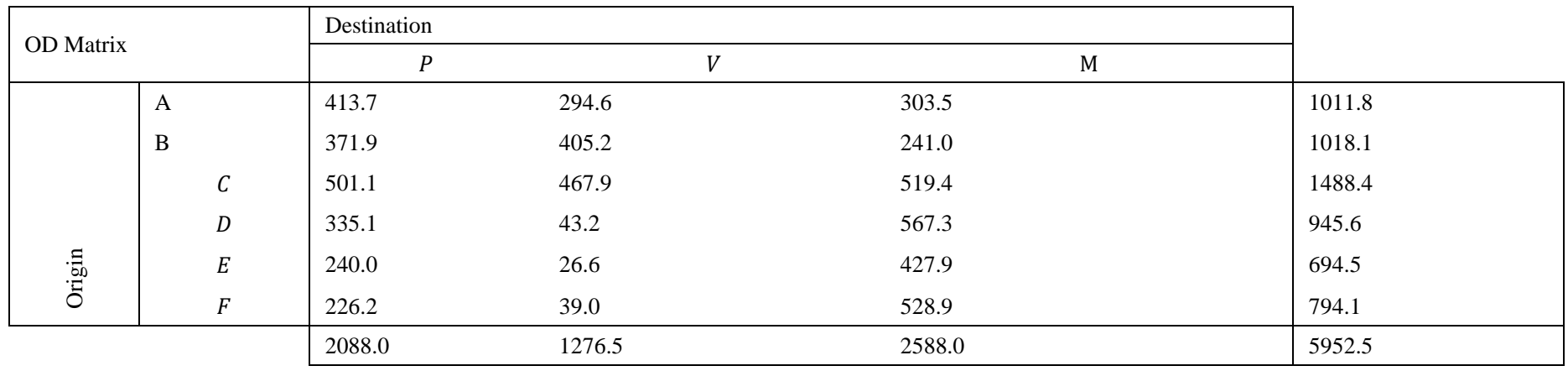

Root Matrix $\square$ OD Matrix estimated

600

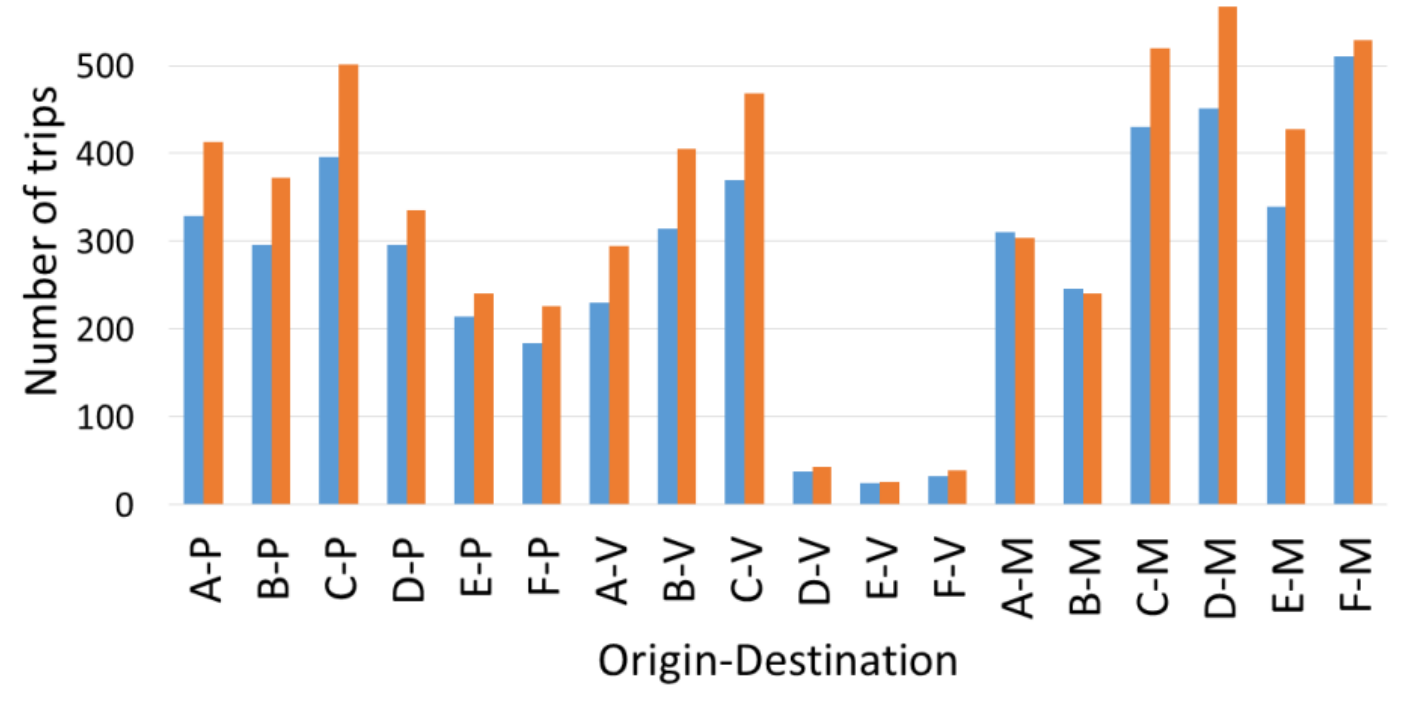

Fig. 2. Number of Trips Root Matrix and OD Matrix Estimated. 


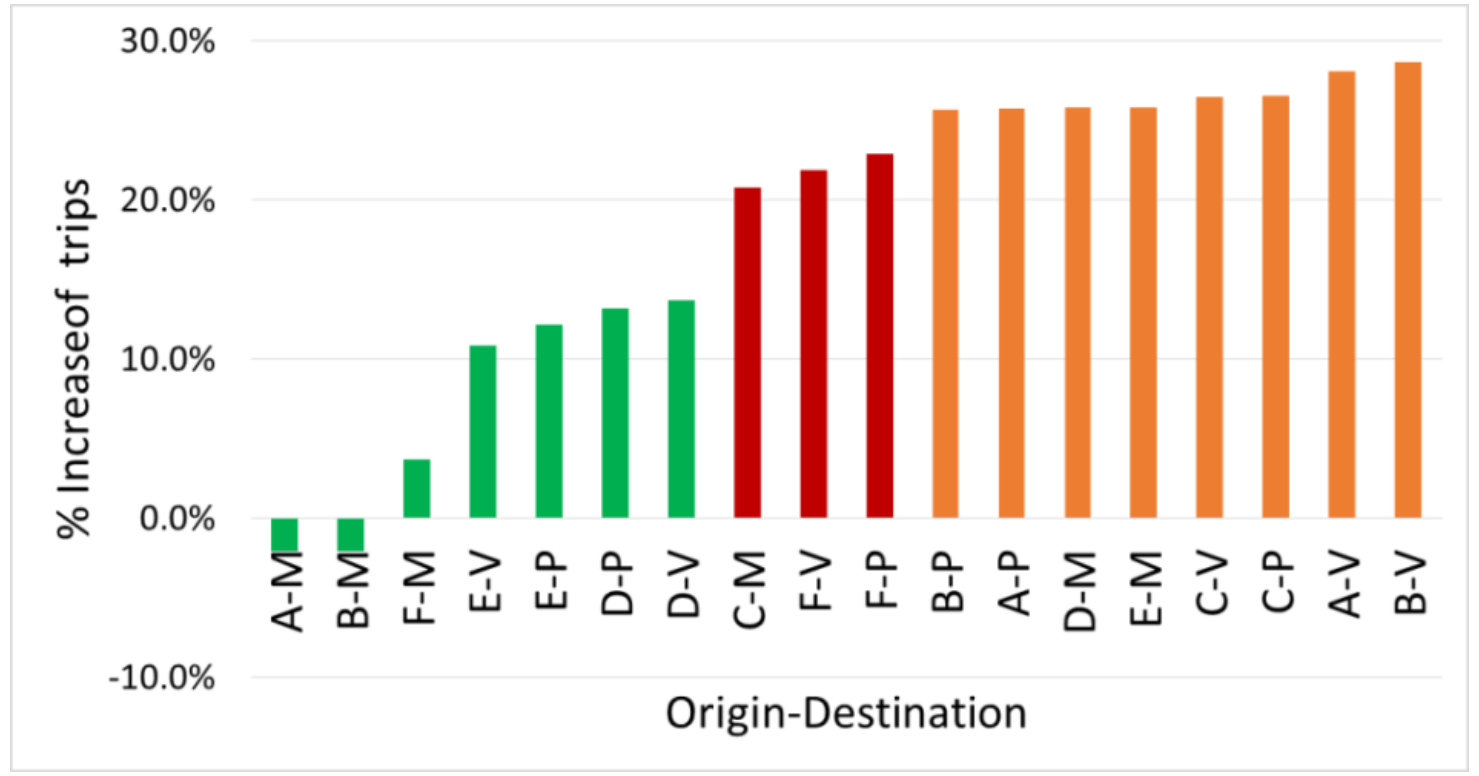

Fig. 3. Percent Increase in Trips Generated.

In relation to the approximation error of the proposed model with the original problem, it was determined $\sum_{(i, j)}\left|R_{i j}-T_{i j} \log \left(T_{i j}\right)\right|$, which had a value of 0.0025 . The error obtained is not significant, demonstrating the advantage of applying the proposed model. Another advantage of the proposed model is its short computational time (few seconds) to solve the problem.

\section{CONCLUSIONS}

In this article, the urban freight transport planning problem is addressed, applying the Entropy Maximization approach to estimate The Origin-Destination Matrix between set of origin zones and destination zones. The difficulty of the Entropy Maximization approach lies in its formulation, which is nonlinear in nature. In order to overcome this difficulty, a MixedInteger Programming Model based on the Piecewise Linear Approximation Method is developed in this paper.

A computational experiment was carried out in a fictitious instance generated from a real case. The application of the proposed mathematical model demonstrated its efficiency in obtaining computational results, with a negligible approximation error and a reduced computational time.

Therefore, the proposed model confirmed its usefulness as a tool to be used in real cases, making the trip estimation satisfactorily.

For future work, the estimation of trips generated by cargo vehicles by type and transit schedules on the roads can be considered.

\section{REFERENCES}

[1] "ISSUES AND PROBLEMS OF MOVING GOODS IN URBAN AREAS," vol. 115, no. 1, pp. 4-19, 1989.

[2] J. Muñuzuri, J. H. R. Van Duin, and A. Escudero, "How efficient is city logistics? Estimating ecological footprints for urban freight deliveries," Procedia - Soc. Behav. Sci., vol. 2, no. 3, pp. 6165-6176, 2010.

[3] L. Dablanc, "Goods transport in large European cities: Difficult to organize, difficult to modernize," Transp. Res. Part A Policy Pract., vol.
41, no. 3, pp. 280-285, 2007.

[4] J. Holguín-Veras and E. Thorson, "Modeling commercial vehicle empty trips with a first order trip chain model," Transp. Res. Part B Methodol., vol. 37, no. 2, pp. 129-148, 2003.

[5] S. Müller, A. Wolfermann, and S. Huber, "A Nation-wide Macroscopic Freight Traffic Model," Procedia - Soc. Behav. Sci., vol. 54, pp. 221$230,2012$.

[6] J. Muñuzuri, P. Cortés, L. Onieva, and J. Guadix, "Estimation of daily vehicle flows for urban freight deliveries," J. Urban Plan. Dev., vol. 138, no. 1, pp. 43-52, 2012.

[7] G. Zenezini and A. De Marco, "A review of methodologies to assess urban freight initiatives," IFAC-PapersOnLine, vol. 49, no. 12, pp. 1359-1364, 2016.

[8] O. Willumsen, J. De Dios Ortúzar, and L. G. Willumsen, MODELLING TRANSPORT. .

[9] R. K. P and S. Mathew, "OD Matrix Estimation from Link Counts Using Artificial Neural Network,” Int. J. Sci. Eng. Res., vol. 4, no. 5, pp. 293296, 2013.

[10] A. Comi and A. Nuzzolo, "Exploring the Relationships between eshopping Attitudes and Urban Freight Transport," Transp. Res. Procedia, vol. 12, no. June 2015, pp. 399-412, 2016.

[11] Z. Gong, "Estimating the urban OD matrix: A neural network approach," Eur. J. Oper. Res., vol. 106, no. 1, pp. 108-115, 1998.

[12] H. Kim, S. Baek, and Y. Lim, "Origin-destination matrices estimated with a genetic algorithm from link traffic counts," Transp. Res. Rec., no. 1771, pp. 156-163, 2001.

[13] S. N. Raman and S. D. Ehsan, "Estimation of freight OD matrix using waybill data and traffic counts in Iran roads," vol. 8, no. 6, pp. 597-613, 2007.

[14] J. Muñuzuri, P. Cortés, L. Onieva, and J. Guadix, "Modeling freight delivery flows: Missing link of urban transport analysis," J. Urban Plan. Dev., vol. 135, no. 3, pp. 91-99, 2009.

[15] L. Novačko, L. Šimunović, and D. Krasić, "Estimation of OriginDestination Trip Matrices for Small Cities," PROMET Traffic\&Transportation, vol. 26, no. 5, pp. 419-428, 2014.

[16] A. E. F. Pérez, "Estimativa de matrizes Origem-Destino para veículos de carga no âmbito do estudo do Plano Diretor de Transporte Urbano da Região Metropolitana de Rio de Janeiro ( PDTU-RMRJ ),” pp. 1-11, 2014.

[17] C. A. Gonzalez-Calderon and J. Holguín-Veras, "Entropy-based freight tour synthesis and the role of traffic count sampling," Transp. Res. Part E Logist. Transp. Rev., vol. 121, no. July 2016, pp. 63-83, 2019. 
[18] C. González and I. Sarmiento, "Trip distribution modeling at Aburra Valley using the gravity model," DYNA, vol. 76, no. 158, pp. 199-207, 2009.

[19] L. M. Bolivar, N. Cruz, and A. Pinto, "Modelo gravitacional del comercio internacional colombiano, 1991-2012," Rev. Econ. y Región, vol. 9, no. 1, pp. 245-270, 2012.
[20] A. Ibeas, J. L. Moura, A. Nuzzolo, and A. Comi, "Urban Freight Transport Demand: Transferability of Survey Results Analysis and Models," Procedia - Soc. Behav. Sci., vol. 54, pp. 1068-1079, 2012.

[21] H. P. Williams, Model building in mathematical programming. John Wiley \& Sons. 2013. 